\title{
Effects of frequency on retrieval from a semantic category
}

\author{
CARL P. DUNCAN \\ Northwestern University, Evanston, Illinois 60201
}

\begin{abstract}
Retrieval of bird names as a function of frequency was compared for recall and for production. As with unrelated words, high-frequency names were about as easily retrieved by either method, but low-frequency names were recalled much better than they were produced. Failure to retrieve some of the very highest frequency names occurred with both retrieval methods, a finding that poses difficulty for some theories of memory.
\end{abstract}

In a previous paper (Duncan, 1973), the effect of frequency on retrieval of a specifiable pool of unrelated words was studied. There were two retrieval methods: free recall and production (trying to think of the words from clues). In production, high-frequency words were retrieved in much greater numbers than lowfrequency words. But in recall (immediately following one presentation of the list), the advantage of high over low frequency was slight. For low-frequency words recall was much better than production, but for high-frequency words recall was little better than production. Only about $50 \%$ of the highest frequency words were retrieved by either method. Once the pool of words to be retrieved was specified, subjects could think of the high-frequency members about as well (or as poorly) as they could recall them after seeing them just once. But low-frequency words were rarely thought of, whereas they were recalled almost as well as high-frequency words.

When subjects are trying to think of a word, it must often be the case that they are attempting to retrieve the name of an object and that the major pool-restricting cue they have is the name of a category to which the object belongs. Such a semantic category contains a number (often large) of related members. Typically, frequency of occurrence of each member of a semantic category in relation to other members is measured and defined by retrieval by production (Murray, 1975). Thus, Battig and Montague (1969) had subjects think of members of several categories, then tabulated the number of subjects that emitted each member.

What is the effect of frequency on retrieval from a semantic category? Can words that are the names of related objects be recalled better than they can be thought of at both high- and low-frequency levels, rather than just at the low-frequency level as in the previous study (Duncan, 1973)?

The Battig-Montague (1969) norms were not com-

The assistance of Christine Bradford is greatly appreciated. pletely satisfactory as a source of materials to help answer this question because in many of their categories frequency of occurrence declines sharply after the first few high-frequency items. Therefore, a study (Duncan, 1975) was done in which 200 subjects were urged to write down many names of birds. Of the more than 100 names emitted, over 50 were listed by at least $10 \%$ of the subjects (vs 18 birds with frequencies of at least $10 \%$ in Battig-Montague). The 48 birds with the highest frequencies of retrieval were used in the present study.

\section{METHOD}

\section{Stimuli}

The high-frequency (HF) list of bird names consisted of the 24 most frequently listed birds (Duncan, 1975, Table 1). In order of production frequency, they were: robin (listed by $95 \%$ of the 200 subjects), eagle, sparrow, cardinal, blue jay, hawk, crow, duck, pigeon, hummingbird, sea gull, chicken, woodpecker, parrot, owl, parakeet, dove, canary, ostrich, pheasant, blackbird, vulture, goose, and turkey (43\%). The mean production frequency of this group of $24 \mathrm{HF}$ bird names was $60.1 \%$; the median was $55.7 \%$.

The low-frequency (LF) list was made up of the 25 th-48th most frequently emitted names. These were: swan (35\%), oriole, bluebird, wren, peacock, pelican, penguin, falcon, flamingo, finch, starling, stork, myna bird, swallow, quail, mockingbird, raven, condor, kingfisher, sapsucker, lark, thrush, chickadee, and albatross (14\%). The mean frequency was $22.9 \%$; the median was $20 \%$.

Each of the $24 \mathrm{HF}$ and the $24 \mathrm{LF}$ bird names was typed on a $2 \times 2$ in. projection slide. Each was arranged in an order such that some of the higher frequency and some of the lower frequency names within the set were distributed throughout the order. Half the subjects were presented the 24 slides in the forward order, half in the reverse order.

\section{Procedure}

The subjects were run in groups of 5-10. The experimenter said, "I will present, one at a time, names of birds. There will be 24 names in all. Each will appear on the projection screen for 2 sec. I want you to try to learn the names. Immediately after we finish going through the list I will give you a sheet with 24 blanks on it. I will ask you to write down as many of the bird names as you remember." After presentation of the list, the subject was told to write down as many bird names as he could in any order. 
Subjects

The subjects were 200 students from introductory psychology courses, 100 presented the HF and 100 the LF list.

\section{RESULTS}

It was the purpose of this study to examine the effect of frequency on retrieval, both by recall and by production. The bird names and their frequencies used were selected from the semantic-category production study (Duncan, 1975); therefore, data from that study will be used as a basis of comparison for the present study.

The 12 highest frequency bird names (Names 1-12 in order of frequency of retrieval from the production study) are called Frequency Level 1 in Table 1. Similarly, Frequency Level 2 consists of Bird Names 13-24 in frequency of retrieval by production, and so on to Level 3 (Names 25-36) and Level 4 (Names 37-48). For each of the four frequency levels, Table 1 shows the mean percent retrieval by production. The mean percent retrieval by recall, from the present study, is also shown for each frequency level. It should be noted that the recall means for Levels 1 and 2 come from those subjects who were presented with, and attempted to recall, the 24 highest frequency bird names; means for Levels 3 and 4 come from the subjects recalling the 24 lowest frequency names.

Table 1 also shows mean percent retrieval by production and by recall for pools of unrelated words. This is the study (Duncan, 1973) in which the words used began with the same initial bigram and were the same length (five letters) but were not meaningfully related to each other.

Looking first at the data for unrelated words, it can be seen that retrieval by production yielded only about half of the available pool or words even at the highest frequency level [Thorndike-Lorge (1944) frequencies of 30 to over 100 per million words]. (The number of words in the pool was 25-28 at each frequency level.) That is, there were many words that subjects are known to have stored (measured by recognition) which they could have thought of but did not. Thus, trying to think of even high-frequency words, given only the initial bigram and the length (despite the fact that several different words fit those cues), is a difficult task. Will

Table 1

Mean Percent Retrieval of Semantically Related Words and of Unrelated Words by Production and by Recall for Different Levels of Frequency

\begin{tabular}{lccccc}
\hline & \multicolumn{2}{c}{ Related } & & \multicolumn{2}{c}{ Unrelated } \\
\cline { 2 - 3 } \cline { 5 - 6 } Frequency & Production & Recall & & Production & Recall \\
\hline 1 (High) & 72.0 & 76.4 & & 48.2 & 52.3 \\
2 & 48.3 & 72.8 & & 36.6 & 43.6 \\
3 & 30.2 & 54.8 & & 18.3 & 44.2 \\
4 & 16.2 & 50.9 & & 6.1 & 33.8 \\
\hline
\end{tabular}

the task be made easier, will retrieval improve, if the same pool of words is shown to subjects once, followed by an immediate attempt to recall? As Table 1 shows, for unrelated words, showing the words to the subject hardly improved retrieval (by recall) even for the highest frequency words. When high-frequency words were defined as members of the same pool by virtue of the structural commonalities of same length and initial bigram, they were equally (or poorly, about 50\%) retrieved by production or recall, even though retrieval by recognition (independently measured in the 1973 study) was $100 \%$ for these highest frequency words.

For lower frequency unrelated words, the picture is quite different. As frequency decreased, production became very poor. At the lowest frequency level (ThorndikeLorge count less than one per million), subjects thought of only $6.1 \%$ of the available pool. At this level some of the failure to retrieve was due to a failure to store; subjects recognized as English words (which all were) only $40 \%$ of these very low-frequency words. However, showing the subject the words for recall greatly improved retrieval, as indicated by the mean of $33.8 \%$ for recall. In short, for unrelated words retrieval by either method ranged from fair for high-frequency words to poor for low-frequency words, but with recall much better than production at low frequencies.

Turning to the related words, it is worth repeating that the frequency dimension is defined by retrieval by production. Thus, the value of $72.0 \%$ in Table 1 is the mean for production (Duncan, 1975) of the 12 most frequently listed bird names. (The other frequency levels also contain 12 names each.) For present purposes, it is only necessary to establish quantitatively the varying frequency with which members of the same semantic category are thought of when the only cue is the name of the category. As Table 1 shows, production frequency does vary rather widely, even for bird names that are stored (from tests of recognition) by essentially all subjects.

In the present study the bird names were shown once to the subject. The subjects were told that they would see only bird names, that the number shown would be 24 , and that they should try to remember them since a recall test would be given. As Table 1 shows, the recall data for these members of the same semantic category follow much the same pattern as was the case for unrelated words. At the highest frequency level, recall was little better than production. But for lowfrequency names, one presentation greatly improves retrieval by recall. Thus, on the whole, the results for both related and unrelated words are quite similar, despite somewhat better retrieval of related words.

\section{DISCUSSION}

When subjects are asked to retrieve words, the pool of words that they should search will typically be defined by structural or semantic, or possibly other, cues. The pool so defined will 
contain a number, of ten a large number, of words. The words in the pool will vary on the dimension of frequency of past experience that subjects have had with the words. This variable has a powerful influence on subjects' attempts to retrieve words from the pool. No matter whether retrieval is measured by production, recognition, or recall, data from the present study and previous studies (Duncan, 1973, 1975) show that retrieval varies directly with frequency.

The effect of frequency is different with each retrieval method. At high-frequency levels, recognition is essentially perfect. Specifically, almost every subject recognizes almost every word. As frequency decreases, recognition continues strong. It is only at the very low frequencies that recognition drops much below $50 \%$.

In a recognition test the words are presented and remain for the subject to see. In a one-trial recall test, the subject sees the words in a specified pool briefly, then must retrieve from memory. If the pool size is larger than the span of apprehension, say 20 words or more, retrieval of the high-frequency words is severely impaired in recall as compared to recognition, dropping from essentailly $100 \%$ to $50 \%-75 \%$. Clearly, something interferes with recall of some of the high-frequency words. Lower frequency words are also not recalled as well as they are recognized, nor recalled as well as the high-frequency words, but this latter difference is not as great as is found with production.

It is in retrieval by production that frequency has its most powerful effect. When a pool of words is defined, the subject can, even without seeing the words at all, use the defining cues to think of the high-frequency members of the pool about as well as he can if he had first seen the words for immediate recall. But he does very poorly on the lower frequencies. Many words that he would recognize instantly and would recall fairly well are thought of, if at all, by very few subjects.

Failure to retrieve low-frequency members of a word pool might be explained simply by the fact that they are of low habit strength because they have not been encountered frequently in the past. But what about the failure of retrieval of highfrequency items? If college students are shown the bird names robin, eagle, sparrow, cardinal, and blue jay (the five most frequently listed in Duncan, 1975) and are asked if they have ever seen the bird names before, it is almost certain that every one of several hundred subjects will say yes; recognition will be $100 \%$. But if another group of subjects is asked to think of bird names, a great many subjects will not list all five names. As many as $5 \%$ will not even list robin, and more than $25 \%$ will not list blue jay. If these five bird names along with other highfrequency names are shown to a subject briefly, failure of retrieval is much the same; each one of the five highest frequency bird names will not be recalled by $10 \%-20 \%$ of the subjects.

Network theories of memory (e.g., Anderson, 1976; Collins \& Loftus, 1975; Wickelgren, 1976) seem to imply that members of a semantic category are linked to one another and, perhaps, to the class name. But the repeated finding of incomplete retrieval of even the most frequent class members raises a problem for such theories. Possibly, the network connections do exist but are weak. Possibly, the elicitation of some members from a network interferes with the emission of others. Collins and Loftus' (1975) use of the physiological concept of spreading activation in a network might be supplemented by another mechanism, viz, inhibition. A process that spreads out from one member of a network may, depending upon strength and distance relations, excite some members but inhibit others.

If members of the same class are indeed weakly connected to each other or to the class name (ordinarily the only retrieval cues), then searching for them is like searching for a few needles in a big haystack. Subjects have stored a very large number of names of objects. In that huge pool, the names of members of one class are a small sample and are apparently not well segregated. In such a case, the probability of thinking of most or all of even the highest frequency members of one class is not great. There are too many possible intrusions, both from names of objects in other classes and from other high-frequency, and even low-frequency, members of the class being searched. Failure to retrieve seems, then, largely attributable to interference.

\section{REFERENCES}

Anderson, J. R. Language, memory, and thought. New York: Halsted, 1976.

Battig, W. F., \& Montague, W. E. Category norms for verbal items in 56 categories: A replication and extension of the Connecticut category norms. Journal of Experimental Psychology Monograph, 1969, 80(No. 3, Part 2), 1-45.

Collins, A. M., Loftus, E. F. A spreading-activation theory of semantic processing. Psychological Review, 1975, 82, 407-428.

Duncan, C. P. Storage and retrieval of low-frequency words. Memory \& Cognition, 1973, 1, 129-132.

Duncan, C. P. Prodded retrieval from a semantic category. Bulletin of the Psychonomic Society, 1975, 6, 61-62.

MurRaY, D. J. Semantically cued retrieval of words from long-term memory. Bulletin of the Psychonomic Society, 1975, 5, 134-136.

ThORNDIKE, E. L., \& LORGE, I. The teacher's word book of 30,000 words. New York: Teachers College, Columbia University Press, 1944.

WICKELGREN, W. A. Network strength theory of storage and retrieval dynamics. Psychological Review, 1976, 83, 466-478.

(Received for publication February 28, 1977.) 